\title{
Cancer Scenario in a Health Care Setting - An Observational Study
}

\author{
Anuj Kapoor ${ }^{1}$, Kamna Singh ${ }^{1}$ \\ ${ }^{1}$ Demonstrator, Department of Community Medicine, GMC Kathua \\ Corresponding Author: Anuj Kapoor
}

\begin{abstract}
Introduction: Cancer can affect all living cells in the body, at all ages and both genders are affected with Cancer. There is a multifactorial causation and the disease process differs at different sites. The World Cancer Report documents that cancer rates are set to increase at an alarming rate globally.

Aim and objectives: To assess the cancer scenario in a tertiary care setting, GMC Kathua

Methodology: This was a hospital-based retrospective study undertaken in the tertiary care center Kathua. GMC, Kathua is one among the five new medical colleges established in Jammu \& Kashmir. The records of cancer patients generated from 1st April 2019 to 31st March 2020 were analyzed. All the cancer cases who reported either for diagnosis in any of the hospital OPD or for the treatment (radiotherapy/ chemotherapy/ surgery) were included. Data was entered in the MS Excel for analysis

Results: A total 254 patients were registered during this 1 year period. Females accounted for $56.2 \%$ and males for $43.07 \%$.Majority of the cases (114) were found in the age group 41-60. CA breast was the common (16.54\%) reported cancer among females followed by CA cervix whereas in males, CA lung $(9.92 \%)$ was the most common reported cancer among males

Conclusion: The prevalence of cancer cases was found to be higher in females as compared to males. The major age group fell in between 41-60 years. The lung was a leading site of cancer among males and breast was a leading site of the cancer among the females.
\end{abstract}

Keywords: Cancer, Breast cancer, Lung cancer.

\section{INTRODUCTION}

Non communicable diseases (NCDs) these days are responsible for the majority of global deaths. ${ }^{1}$ Cancer incidence and mortality are rapidly growing worldwide, both in the developed and developing countries and is currently the second leading cause of death in the world. ${ }^{2}$ The reasons are complex and includes higher life expectancy and adoption of cancer linked lifestyle such as smoking and physical inactivity. ${ }^{3}$ situation is made worse by the lack of early detection and access to treatment. ${ }^{4}$ According to Globocan 2018, an estimated of 18.1 million new cancer cases (17.0 million) and 9.6 million cancer deaths (9.5 million) deaths were reported. The most common cancer diagnosed were lung cancer
2.09 million (11.6\%), followed by cancer breast 2.08 million (11.6\%). The most common cause of cancer deaths were cancer lung (18.4\%), colorectal cancer (9.2\%), cancer stomach $(8.2 \%)$, cancer liver $(8.2 \%)$ and cancer breast $(6.6 \%)$. ${ }^{5}$ Prevalence of cancer in India is estimated to be 3.9 million and reported incidence to be about 1.1 million. ${ }^{6}$ There is wide variation in the distribution of the cancer throughout the world. In India most common cancer is cancer lung among males and cancer breast among females. Cancer of stomach is very common in Japan whereas it has low incidence in United States. These and other international variations in the pattern of the cancers are attributed to multiple factors such as environmental factors, food habits, 
lifestyle, genetic factors or even inadequacy in detection and reporting of cases. ${ }^{7,8}$ The present study was undertaken to determine the pattern and scenario of cancer cases reporting to tertiary care hospital located in this region. An epidemiological study helps to know the common cancers prevalent in particular segments of the population and risk factors involved. This helps in planning the facilities required in a hospital.

\section{METHODOLOGY}

This was a hospital-based retrospective study undertaken in the Government Medical College Kathua. GMC, Kathua is one among the five new medical colleges established in Jammu \& Kashmir. The records of cancer patients generated from $1^{\text {st }}$ April 2019 to $31^{\text {st }}$ March 2020 were analyzed. All the cancer cases who reported either for diagnosis in any of the hospital OPD (Medicine, Gynae and Obs, pediatrics, Surgery, orthopedics, ENT, ophthalmology etc) or for the treatment (radiotherapy/ chemotherapy/ surgery) were included. Information regarding age, sex, residence, diagnosis, plan of treatment and follow up was collected. Data was entered in the MS Excel and descriptive analysis was done.

\section{RESULTS}

A total 254 patients were registered during this 1 year period. Females accounted for $56.2 \%$ and males for $43.7 \%$ (Fig.1). Majority of the cases (114) were found in the age group 41-60. Out of this 114, 72 were females and 42 males. Least cases were found in the age group 0-20 (Table1, Fig2).

CA breast was the common (16.54\%) reported cancer among females followed by CA cervix. Maximum cases of breast cancer were in the age group 41-60. 1 case each of CA oral cavity, rectum, thyroid and cranial cavity was reported. (Table 2) Whereas in males, CA lung $(9.92 \%)$ was the most common reported cancer among males followed by CA larynx $(4.04 \%)$. Lung cancer was most common in the age group of 61-80 years. (Table 3)

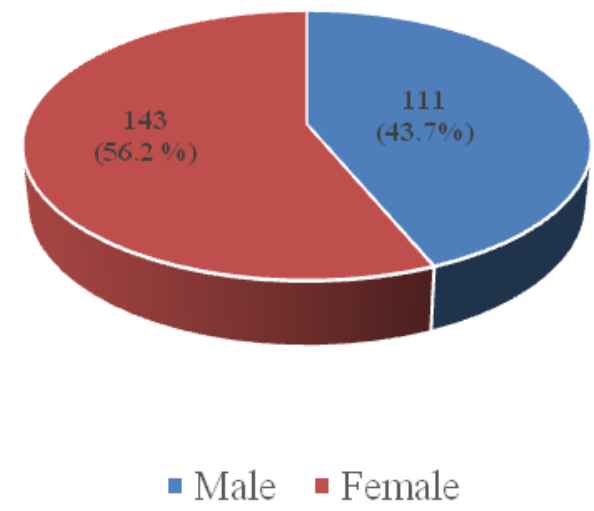

Fig 1: Sex wise distribution of the registered patients

Table 1: Age wise distribution of the cancer cases

\begin{tabular}{|c|c|c|c|}
\hline Age groups (years) & Males & Females & Total \\
\hline $0-20$ & 1 & 2 & $3(1.1 \%)$ \\
\hline $21-40$ & 11 & 26 & $37(13.6)$ \\
\hline $41-60$ & 42 & 72 & $114(44.8 \%)$ \\
\hline $61-80$ & 50 & 43 & $93(36.6)$ \\
\hline$>80$ & 4 & 3 & $7(2.5 \%)$ \\
\hline
\end{tabular}

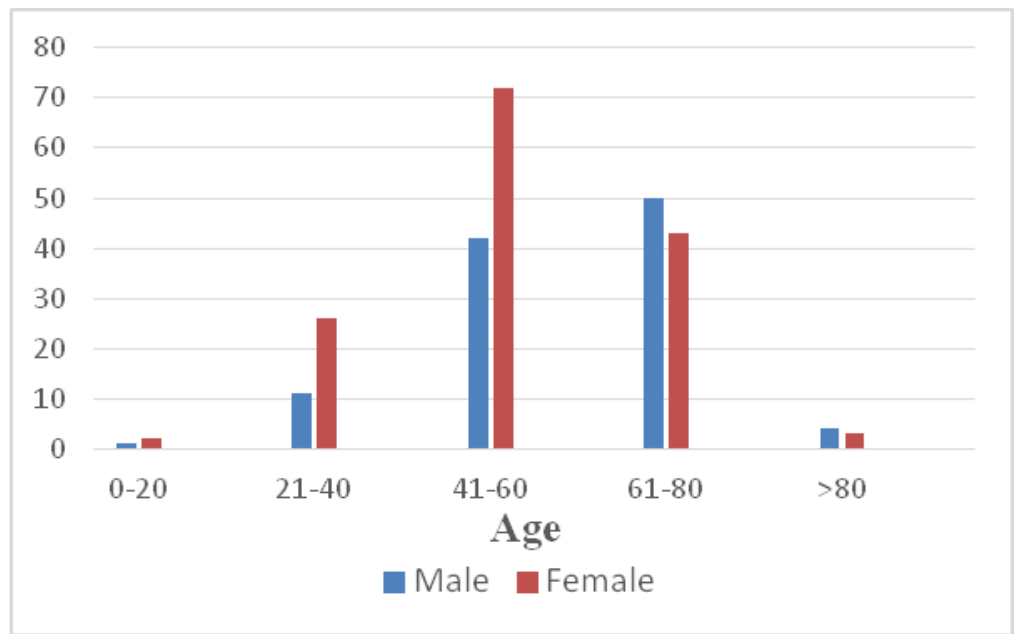

Fig 2: Age wise distribution of the cancer cases 
Anuj Kapoor et.al. Cancer scenario in a health care setting -an observational study.

Table 2: Frequency distribution of cancer cases among females (n-272)
\begin{tabular}{|l|c|c|c|c|c|c|}
\hline & \multicolumn{7}{|c|}{ Age groups } \\
\hline Type of cancer & $\mathbf{0 - 2 0}$ & $\mathbf{2 1 - 4 0}$ & $\mathbf{4 1 - 6 0}$ & $\mathbf{6 1 - 8 0}$ & $\mathbf{> 8 0}$ & $\mathbf{n}(\% \mathbf{a g e})$ \\
\hline Breast & 2 & 7 & 15 & 6 & & $30(11.8)$ \\
\hline Cervix & & & 10 & 8 & & $18(7.0)$ \\
\hline Hematological & & 6 & 8 & 2 & & $16(6.2)$ \\
\hline Lungs & & & 3 & 10 & & $13(4.77)$ \\
\hline Endometrial & & & 7 & 5 & & $12(4.41)$ \\
\hline Gall bladder & & 1 & 7 & 3 & 1 & $12(4.41)$ \\
\hline Ovarian & & 1 & 2 & 2 & & $5(1.83)$ \\
\hline RCC & & 1 & 2 & & 1 & $4(1.47)$ \\
\hline Esophageal & & & 3 & 1 & & $4(1.47)$ \\
\hline Pancreas & & 1 & 1 & 1 & 1 & $4(1.47)$ \\
\hline Stomach & & 1 & 2 & & & $3(1.10)$ \\
\hline Larynx & & & 1 & 2 & & $3(1.10)$ \\
\hline Bone & & 2 & & 1 & & $3(1.10)$ \\
\hline Liver & & 1 & 1 & & & $2(0.73)$ \\
\hline Colon & & & 2 & & & $2(0.73)$ \\
\hline Urinary bladder & & & & 2 & & $2(0.73)$ \\
\hline Oral cavity & & & 1 & & & $1(0.36)$ \\
\hline Rectum & & & & 1 & & $1(0.36)$ \\
\hline Cranial & & 1 & & & & $1(0.36)$ \\
\hline Thyroid & & & 1 & & & $1(0.36)$ \\
\hline
\end{tabular}

Table 3: Frequency distribution of cancer cases among males (n-272)

Table 3: Frequency distribution of cancer cases among males (n-272)
\begin{tabular}{|l|c|c|c|c|c|c|}
\hline & \multicolumn{7}{|c|}{ Age groups } \\
\hline Type of Cancer & $\mathbf{0 - 2 0}$ & $\mathbf{2 1 - 4 0}$ & $\mathbf{4 1 - 6 0}$ & $\mathbf{6 1 - 8 0}$ & $\mathbf{> 8 0}$ & $\mathbf{n}(\% \mathbf{a g e})$ \\
\hline Lungs & & & 11 & 14 & 2 & $27(9.92)$ \\
\hline Larynx & & & 6 & 5 & & $11(4.04)$ \\
\hline Hematological & & 3 & 2 & 6 & & $11(4.04)$ \\
\hline Oral cavity & & 1 & 6 & 2 & & $9(3.30)$ \\
\hline Prostate & & & 1 & 6 & 2 & $9(3.30)$ \\
\hline Esophagus & & & 5 & 3 & & $8(2.94)$ \\
\hline Urinary Bladder & & & 3 & 3 & & $6(2.20)$ \\
\hline Rectum & & 1 & 3 & 2 & & $6(2.20)$ \\
\hline Bone & 1 & 3 & 1 & 1 & & $6(2.20)$ \\
\hline Gall bladder & & & 3 & 1 & & $4(1.47)$ \\
\hline Colon & & & 3 & 1 & & $4(1.47)$ \\
\hline Thyroid & & 1 & 1 & 2 & & $4(1.47)$ \\
\hline RCC & & & & 3 & & $3(1.10)$ \\
\hline Pancreas & & 1 & & 2 & & $3(1.10)$ \\
\hline Liver & & 1 & & 2 & & $3(1.10)$ \\
\hline Cranial & & & 1 & 1 & & $2(0.73)$ \\
\hline Duodenum & & & 1 & & & $1(0.36)$ \\
\hline
\end{tabular}

\section{DISCUSSION}

Epidemiological information on cancer including the pattern is an important basis for determining the priorities for cancer control in any population group. A total 254 patients were registered in the hospital over 1 year period. The most common cancer in adult females was found to be $\mathrm{Ca}$ breast followed by $\mathrm{Ca}$ cervix whereas in males Carcinoma lung was the most common cancer followed by $\mathrm{Ca}$ larynx. In present study with male female ratio was $0.77: 1$ indicating female predominance. Similar pattern was recorded by Cherian et al in Kerala (0.93:1) ${ }^{9}$; which was higher than Jabalpur study of Sinha et al $(0.66: 1)^{10}$ and Kalyani et al in Kolar $(0.7: 1)^{11}$. Though male predominance was recorded by Sharma et al in Jaipur region (1.4:1) and Wani et al in Kashmir valley (3:2) ${ }^{12,13}$ The most affected female age groups in our study were 41-60, with $50.3 \%$ occurrence, while males in the age groups of 61-80, with $45.02 \%$ occurrence. According to the study by Zeb et al, for females, the most affected age group was 41-50, with $8.87 \%$ occurrence, and the second most affected age group was 51-60, with $6.88 \%$ occurrence. For males, the most affected age group was $51-60$, with $12.3 \%$ occurrence, followed by $61-70$, with $10.32 \%$ occurrence. ${ }^{14}$ In males, lung cancer was the most common followed by larynx. Cancers in males are mostly tobacco related. Lung was found to be the most common site in Jammu study, whereas larynx malignancies 
were more in Ludhiana \& Bankura in West Bengal ${ }^{14,15,16}$ Report from hospital based cancer registry 2007-11 under NCRP showed lung to be the top site for malignancy in males in Chandigarh \& Thiruvananthapuram, whereas it is the second most common carcinoma in Mumbai \& Chennai registries ${ }^{17}$. Carcinoma breast $(11.8 \%)$ was the most common cancer in adult females in our study followed by $\mathrm{Ca}$ cervix (7\%). Breast cancer is proportionately on the increase and is related to late marriage, birth of the first child at a late age, fewer children and shorter period of breast feeding which are increasingly common practices among educated urban women. Our data was comparable to $22.46 \%$ in Ambajogai, $20.44 \%$ in Jaipur, $21.05 \%$ in Ludhiana \& $19.4 \%$ in Eastern Rajasthan. ${ }^{8,18,19}$

\section{CONCLUSION}

The prevalence of cancer cases was found to be higher in females as compared to males. The major age group fell in between 41-60 years. The lung was a leading site of cancer among males and breast was a leading site of the cancer among the females.

\section{Financial Support and Sponsorship Nil}

\section{Conflicts of Interest}

There are no conflicts of interest

\section{Acknowledgement: None}

\section{Ethical Approval: Approved}

\section{REFERENCES}

1. World Health Organization. Global Health Observatory. Geneva: World Health Organization; 2018.

2. Torre LA, Islami F, Siegel R L, Ward EM \& Jemal A. Global cancer in women: burden and trends. AACR. 2017

3. World Health Organization. The Global Burden of Disease: 2004 Update. Geneva: World Health Organization; 2008.
4. WHO (2013), Press Release No.223, 12 Dec. Latest World Cancer Statistics

5. WHO 2018: Global Cancer Observatorty, September 2018

6. Call for Action; Expanding cancer care for women in India, Sept,21,2017, FICCI and EY

7. Park K. Epidemiology of communicable diseases. Park's Textbook of Preventive and Social Medicine. 25th ed. Jabalpur: Banarsidas Bhanot Publishers; 2005: 146.

8. Sharma RG, Kumar R, Jain S, Jhajhria S, Gupta N, Gupta SK. Distribution of malignant neoplasms reported at different pathology centers and hospitals in Jaipur, Rajasthan. Indian J Cancer. 2009; 46:32330.

9. Cherian T, Mahadevan P, Chandramathi S, et al. Increasing cancer incidence in a tertiary care hospital in a developing country, India. Indian J Cancer. 2015;52(1) :133-139.

10. Sinha A, Kasar PK, Tiwari R, et al. Cancer Morbidity and Mortality Profile in Jabalpur - A Hospital Based Study. Indian J Community Med. 2006;31(1):16-17.

11. Damodar G, Gopinath S, Vijayakumar S, et al. Reasons for Low Quality of Life in South Indian Cancer Patient Population_:A Prospective Observational Study. Indian J Pharm Sci. 2014;(February):2-9.

12. Kalyani R, Das S, Bindra Singh MS, et al. Cancer profile in the Department of Pathology of Sri Devaraj Urs Medical College, Kolar: a ten years study. Indian J Cancer. 2010;47(2):160-165.

13. Sharma RG, Kapoor R, Bang BA, et al. Spectrum of malignancies in Jaipur region (2004-2008). Indian J Cancer. 2014;51(1): 45-53.

14. Zeb A, Rasool A, Nasreen S (2008). Cancer Incidence in the Districts of Dir (North West Frontier Province), Pakistan: A Preliminary Study. J Chin Med Assoc, 71, 2

15. Gaur DS, Kishore S, Harsh M, Kusum A, Bansal R. Pattern of cancers amongst patients attending Himalayan Institute of Medical Sciences, Dehradun. Indian J PatholMicrobiol. 2006; 49:193-98.

16. Kapoor R, Goswami KC, Kapoor B, Dubey VK. Pattern of cancer in Jammu region (hospital based study 1978-87). Indian J Cancer. 1993;30:67-71. 
17. Sharma RG, Ajmera R, Saxena O. Cancer profile in eastern Rajasthan. Indian $\mathbf{J}$ Cancer. 1994;31:160-73.

18. NCDIR (NCRP) - Consolidated Report of Hospital Based Cancer Registries 20072011, National Centre for Disease Informatics and Research (Indian Council of Medical Research) Bangalore, 2013:6-10

19. Malhotra V, Shah BS, Sabharwal S. Pattern of Cancer in Dayanand Medical College \& Hospital, Ludhiana (a ten year retrospective study). Indian J Pathol Microbiol. 2001;44: 27-30.
20. Kulkarni PV, Jaiswal SS, Rathod SB, Khalique A, KulkarniRRProfile of malignancies at Medical College, Ambajogai- (15 years retrospective study). Indian J Cancer. 1996;33:31-36.

How to cite this article: Kapoor A, Singh K. Cancer scenario in a health care setting -an observational study. Int J Health Sci Res. 2021; 11(5): 236-240. DOI: https://doi.org/10.52403/ ijhsr.20210538 